\title{
ANALISIS KADAR ZAT ADITIF PADA MINUMAN SIRUP RASA MARQUISA
}

\author{
Nyoman Sri Ariantini \\ Universitas Pendidikan Ganesha \\ Singaraja, Indonesia \\ e-mail: rejito89@gmail.com
}

\begin{abstract}
Abstrak
Penelitian ini bertujuan untuk mengetahui (1) apakah minuman sirup rasa marquisa yang diuji di Laboratorium Pangan dan Bahan Berbahaya, dan disampling di pasar Badung oleh bagian Pemeriksaan dan Penyelidikan mengandung zat aditif (benzoat, sorbat, sakarin), (2) kadar zat aditif (benzoat, sorbat, sakarin) yang terkandung dalam minuman sirup rasa marquisa, (3) apakah kadar zat aditif (benzoat, sorbat, sakarin) yang telah diperoleh memenuhi syarat yang telah ditetapkan Pemerintah melalui Peraturan Menteri Kesehatan No.722/Menkes/PER/IX/88, dan Standar Nasional Indonesia (SNI) 01-3544-1994. Subyek pada penelitian ini adalah minuman sirup rasa marquisa yang diambil dari Laboratorium Pangan dan Bahan Berbahaya BBPOM Denpasar, dan disampling di pasar Badung oleh bagian Pemeriksaan dan Penyelidikan (Pemdik) BBPOM Denpasar, sedangkan obyek pada penelitian ini adalah kadar zat aditif (benzoat, sorbat, sakarin). Penelitian ini adalah jenis penelitian deskriptif yang bertujuan untuk memberikan gambaran atau deskripsi mengenai kadar zat aditif (benzoat, sorbat, sakarin) dalam minuman sirup rasa marquisa. Penetapan kadar zat aditif (benzoat, sorbat, sakarin) dilakukan dengan metode HPLC. Hasil penelitian ini menunjukkan (1) minuman sirup rasa marquisa yang diuji di Laboratorium Pangan dan Bahan Berbahaya BBPOM Denpasar, dan disampling di pasar Badung oleh bagian Pemeriksaan dan Penyelidikan (Pemdik) BBPOM Denpasar, mengandung pengawet benzoat yang melebihi batas maksimum yang diizinkan oleh Peraturan Menteri Kesehatan No.722/Menkes/PER/IX/88, dan Standar Nasional Indonesia (SNI) 01-3544-1994 yaitu berkisar antara 1291,31-1632,40 ppm, (2) minuman sirup rasa marquisa ini juga mengandung pemanis sakarin yang berkisar antara 434,62-1029,24 ppm, (3) tetapi minuman sirup rasa marquisa ini tidak mengandung pengawet sorbat.
\end{abstract}

Kata kunci: Minuman Sirup Rasa Marquisa, Benzoat, Sorbat, Sakarin

\section{Pendahuluan}

Sirup merupakan salah satu produk minuman yang banyak diminati oleh masyarakat luas, karena rasanya yang sangat menyegarkan. Salah satu minuman sirup yang banyak dikonsumsi oleh masyarakat luas adalah minuman sirup rasa marquisa. Dibalik enak dan segarnya sirup rasa marquisa tidak jarang sirup rasa marquisa mengandung zat aditif yang dapat menimbulkan gangguan kesehatan yang cukup serius bagi konsumen. Zat aditif sengaja ditambahkan oleh produsen dengan tujuan menampilkan makanan atau minuman menjadi semenarik mungkin baik dari segi warna, rasa, aroma, dan tekstur (Imam dan Sukanto, 1999). Akan tetapi, acap kali faktor gizi, higienis dan keamanan untuk dikonsumsi justru terabaikan.

Menurut Standar Nasional Indonesia (SNI) 01-3544-1994, sirup adalah larutan gula pekat (sakarosa "high fructose syrup" dan atau gula inversi lainnya) dengan atau tanpa penambahan zat aditif makanan yang diizinkan.

Sirup memiliki kandungan air yang cukup besar karena hampir $70 \%$ dari beratnya mengandung air, sedangkan sisanya adalah berupa gula, aroma buah, dan zat aditif lainya yang ditambahkan pada sirup seperti bahan pengawet, pewarna, pengental dan lain sebagainya (Sujiono, 1999).

Menurut Peraturan Menteri Kesehatan R.I No.329/Menkes/Per/XII/76, yang dimaksud dengan zat aditif adalah bahan yang ditambahkan dan dicampurkan sewaktu pengolahan makanan atau minuman untuk meningkatkan mutu (Winarno, 2002 : 214). Bahan-bahan yang termasuk zat aditif antara lain : pewarna, penyedap rasa dan aroma, antioksidan, pengawet, pengemulsi, antigumpal, pemucat, dan pengental. 
Bahan pengawet adalah zat aditif yang bertujuan untuk menghambat atau mencegah fermentasi, pengasaman, atau peruraian lain terhadap makanan yang disebabkan oleh mikroorganisme (bakteri, kapang, khamir) sehingga dapat meningkatkan daya simpan suatu produk olahan. Asam Benzoat $\left(\mathrm{C}_{6} \mathrm{H}_{5} \mathrm{COOH}\right)$ merupakan bahan pengawet yang luas penggunaannya dan sering digunakan pada bahan makanan yang asam. Benzoat pada umumnya efektif terhadap khamir dan jamur daripada bakteri, dan efektif pada $\mathrm{pH}$ 2,5-4,0. Tetapi diduga molekul-molekul asam benzoat yang tidak mengalami disosiasi diduga merupakan komponen aktif yang mematikan (Destrosier, 1988 : 388). Asam sorbat $\left(\mathrm{CH}_{3}-\right.$ $\mathrm{CH}=\mathrm{CH}-\mathrm{CH}=\mathrm{CHCOOH}$ ) adalah salah satu bahan pengawet organik yang banyak digunakan untuk mengawetkan bahan pangan seperti daging, ikan, sayuran segar, keju, dan sirup. Mekanisme asam sorbat dalam mencegah pertumbuhan mikroba adalah dengan mencegah kerja enzim dehidrogenase terhadap asam lemak, dan struktur $\alpha$-diena pada asam sorbat dapat mencegah oksidasi asam lemak oleh enzim tersebut (Winarno, 2002 : 224). Zat aditif lain yang juga biasa ditambahkan adalah bahan pemanis sitetis merupakan bahan yang dapat menimbulkan rasa manis atau dapat membantu mempertajam penerimaan terhadap rasa manis tersebut, sedangkan kalori yang dihasilkan jauh lebih rendah daripada gula. Umumnya bahan pemanis sintetik mempunyai struktur kimia yang berbeda dengan struktur polihidrat gula alam. Meskipun telah banyak ditemukan bahan pemanis sintetik, tetapi hanya beberapa saja yang diperbolehkan pemakaiannya pada bahan pangan. (Winarno, $2002: 218$ )

Penggunaan sakarin sebagai pemanis pada minuman jenis sirup telah dilarang menurut peraturan Menteri Kesehatan No.722/Menkes/PER/IX/88, dan Standar Nasional Indonesia (SNI) 01-3544-1994, karena menurut penelitian penggunaan sakarin dapat menimbulkan resiko yang cukup serius terhadap kesehatan konsumen utamanya dapat merangsang terjadinya tumor di kandung kemih (Winarno, $2002: 218$ ).

High Performance Liquid Chromatography atau High Pressure Liquid Chromatography (HPLC) merupakan jenis kromatografi yang luas pemakaiannya, karena sangat sensitif. Metode ini cocok untuk analisis kuantitatif yang akurat, karena kemampuannya untuk memisahkan senyawa yang mudah menguap atau senyawa yang peka terhadap panas (Sastrohamidjojo, 1995 dalam Wahyuningsih, 1999). Mengingat sifat dari benzoat, sorbat, dan sakarin yang sangat peka terhadap panas maka sangat cocok untuk dianalisis dengan menggunakan alat HPLC. Pada pemisahan dengan menggunakan HPLC, sampel diinjeksikan ke dalam injektor, kemudian pelarut atau fase geraknya juga diinjeksikan kemudian dipompa melewati fase diam yang terdapat pada kolom. Komponen yang diikat secara kuat oleh fase diam akan bergerak lambat oleh aliran fase gerak, sebaliknya komponen yang tidak diikat secara kuat oleh fase diam akan bergerak cepat. Sebagai akibat dari perbedaan kecepatan pergerakan komponenkomponen tersebut maka komponen dalam Subjek itu akan terpisah menjadi lapisan-lapisan tersendiri yang kemudian dapat dianalisis. Analisis kromatografi adalah suatu proses berdasarkan pada prinsip distribusi fase, yaitu suatu perpindahan komponen-komponen zat yang dianalisis dari suatu fase yang bergerak menuju ke fase lain yang diam yang dilaluinya (Sastrohamidjojo, 1995 dalam Wahyuningsih, 1999). Untuk mengetahui ada tidaknya zat aditif (benzoat, sorbat dan sakarin) dalam minuman sirup rasa marquisa dengan menggunakan alat HPLC adalah sebagai berikut: Larutan baku benzoat, sorbat, dan sakarin diinjeksikan ke dalam alat HPLC dengan konsentrasi yang berbeda-beda untuk mendapatkan waktu retensi dari larutan baku benzoat, sorbat, dan sakarin. Waktu retensi munculnya kromatogram hasil injeksi larutan baku digunakan sebagai acuan untuk menentukan waktu retensi dan puncak kromatogram dari larutan sampel yang akan diuji. Bila waktu retensi munculnya puncak kromatogram larutan uji tersebut sama dengan waktu retensi larutan baku benzoat, sorbat, dan sakarin, maka puncak kromatogram itulah yang dipilih sebagai puncak kromatogram larutan sampel yang akan diuji (Sastrohamidjojo, 1995 dalam Wahyuningsih, 1999).

Bahan pengawet adalah salah satu zat aditif yang biasa ditambahkan pada minuman sirup, dengan tujuan untuk menghambat atau menghentikan aktivitas mikroba (bakteri, kapang, khamir) sehingga dapat meningkatkan daya simpan suatu produk olahan (Hudaya, 1984 : 87). Bahan pengawet yang biasa ditambahkan pada minuman sirup adalah jenis benzoat dan sorbat karena dipandang cukup efektif untuk menekan pertumbuhan mikroorganisme pada minuman sirup. Seringkali produk minuman sirup yang beredar di pasaran mengandung pengawet jenis ini dengan kadar yang melebihi batas maksimum yang diizinkan oleh pemerintah, dalam hal ini Departemen Kesehatan. Menurut peraturan Menteri Kesehatan RI No 722/Menkes/PER/IX/88, dan Standar Nasional Indonesia (SNI) 01-3544-1994, batas maksimum bahan pengawet yang diizinkan untuk ditambahkan pada sirup adalah 1000 ppm. Zat aditif lain yang biasa juga ditambahkan pada minuman sirup adalah pemanis sintetis, salah satunya adalah sakarin. 
Menurut Peraturan Menteri Kesehatan RI No. 722/Menkes/PER/IX/88, dan Standar Nasional Indonesia (SNI) 01-3544-1994, pemakaian sakarin sebagai pemanis sama sekali tidak diperbolehkan karena dapat menimbulkan gangguan kesehatan yang cukup serius, utamanya mengakibatkan terjadinya tumor kandung kemih.

Berdasarkan hal tersebut, maka dalam penelitian ini dilakukan analisis kadar dari masingmasing zat aditif (benzoat, sorbat, dan sakarin) pada sirup rasa marquisa yang beredar di pasaran.

\section{Metode}

Penelitian Jenis penelitian ini adalah penelitian deskriptif yang bertujuan untuk memberikan gambaran atau deskripsi mengenai kadar zat aditif dalam hal ini benzoat, sorbat, dan sakarin dalam minuman sirup rasa marquisa dan untuk mengetahui apakah kadar zat aditif tersebut memenuhi persyaratan yang telah ditetapkan dalam Peraturan Menteri Kesehatan No.722/Menkes/PER/IX/88, dan Standar Nasional Indonesia (SNI) 01-3544-1994.

Pada penelitian ini peneliti tidak melakukan sampling langsung dilapangan, melainkan sampel diambil oleh bagian Pemeriksaan dan Penyelidikan (Pemdik) BBPOM Denpasar. Sampel yang digunakan disampling di pasar Badung oleh bagian Pemeriksaan dan penyelidikan (Pemdik) BBPOM Denpasar dengan jumlah 5 buah dengan jenis yang sama. Dari bagian Pemdik sampel kemudian diuji di Laboratorium Pangan dan Bahan Berbahaya.

\section{Hasil dan Pembahasan}

Setelah Dari persamaan kurva baku benzoat yang telah didapat $(Y=3343,27+$ $51139,37 X)$ maka konsentrasi benzoat (X) pada masing-masing sampel dapat ditentukan

Dari data yang diperoleh dan pengolahan data yang telah dilakukan diperoleh kadar benzoat pada masing-masing sampel seperti ditunjukkan pada Tabel 1.

Tabel 1. Kadar Benzoat Pada Sampel Sirup Rasa Marquisa.

\begin{tabular}{cccccc}
\hline No sampel & $\begin{array}{c}\text { Berat sampel } \\
(\mathbf{W})\end{array}$ & $\mathbf{f p}$ & $\mathbf{V p}(\mathbf{m L})$ & $\begin{array}{c}\text { Konsentrasi } \\
\text { hasil } \\
\text { pengukuran } \\
(\mathbf{X})\end{array}$ & $\begin{array}{c}\text { Kadar } \\
\text { benzoat } \\
\text { (ppm) }\end{array}$ \\
\hline 1 & 5,3385 & $10 \mathrm{kali}$ & 50 & 14,216 & 1338,25 \\
2 & 5,2025 & $10 \mathrm{kali}$ & 50 & 16,899 & 1632,40 \\
3 & 5,0235 & $10 \mathrm{kali}$ & 50 & 12,908 & 1291,31 \\
4 & 5,3475 & $10 \mathrm{kali}$ & 50 & 16,899 & 1588,14 \\
5 & 5,0025 & $10 \mathrm{kali}$ & 50 & 16,111 & 1618,50 \\
\hline
\end{tabular}

Dari kromatogram yang dihasilkan oleh alat HPLC, tidak ditemukan respon puncak atau yang menunjukan adanya pengawet sorbat pada masing-masing sampel.

Tabel 2. Tabel penimbangan masing-masing sampel

\begin{tabular}{ccc}
\hline No Sampel & Penimbangan & Respon puncak \\
\hline Sampel 1 & 5,3385 & - \\
Sampel 2 & 5,2025 & - \\
Sampel 3 & 5,0235 & - \\
Sampel 4 & 5,3475 & - \\
Sampel 5 & 5,0025 & - \\
\hline
\end{tabular}

Dari persamaan kurva baku sakarin yang telah didapat $(Y=-313,53+55962,38 X)$ maka konsentrasi sakarin $(X)$ pada masing-masing sampel dapat ditentukan

Dari data yang diperoleh dan pengolahan data yang telah dilakukan (perhitungan kadar sakarin dapat ditunjukkan pada Lampiran 04) diperoleh kadar sakarin pada masing-masing sampel seperti ditunjukkan pada Tabel 3. 
Tabel 3. Penetapan Kadar Sakarin Pada Sirup Rasa Marquisa.

\begin{tabular}{cccccc}
\hline No sampel & $\begin{array}{c}\text { Berat sampel } \\
(\mathbf{W})\end{array}$ & fp & $\mathbf{V p}(\mathbf{m L})$ & $\begin{array}{c}\text { Konsentrasi } \\
\text { hasil } \\
\text { pengukuran } \\
(\mathbf{X})\end{array}$ & $\begin{array}{c}\text { Kadar } \\
\text { sakarin } \\
(\mathbf{p p m})\end{array}$ \\
\hline 1 & 5,3385 & $10 \mathrm{kali}$ & 50 & 4,831 & 452,01 \\
2 & 5,2025 & $10 \mathrm{kali}$ & 50 & 10,720 & 1029,24 \\
3 & 5,0235 & $10 \mathrm{kali}$ & 50 & 4,371 & 434,62 \\
4 & 5,3475 & $10 \mathrm{kali}$ & 50 & 10,720 & 1001,33 \\
5 & 5,0025 & $10 \mathrm{kali}$ & 50 & 10,240 & 1022,46 \\
\hline
\end{tabular}

Dari data hasil penelitian yang diperoleh, maka secara umum minuman sirup rasa marquisa yang diuji di Laboratorium Pengujian Pangan dan Bahan Berbahaya BBPOM Denpasar positif mengandung zat aditif yaitu pengawet benzoat dan pemanis sakarin. Dari data pada Tabel 4.1 diperoleh kadar benzoat yang bervariasi pada masing-masing sampel yaitu berkisar antara 1291,31-1632,40 ppm.

Memperhatikan kadar benzoat pada masing-masing sampel jika dibandingkan dengan batas maksimum yang diizinkan oleh pemerintah melalui Peraturan Menteri Kesehatan RI No. 722/Menkes/PER/IX/88, dan Standar Nasional Indonesia (SNI) 01-3544-1994, maka kadar pengawet benzoat pada masing-masing sampel dapat dikatakan tidak nmemenuhi syarat karena kadarnya melebihi batas maksimum yang telah ditetapkan yaitu sebesar 1000 ppm. Jika minuman sirup rasa marquisa dengan kadar pengawet benzoat yang melebihi batas maksimum yang telah ditetapkan pemerintah dikonsumsi oleh masyarakat secara kontinyu maka dapat menimbulkan masalah kesehatan yang cukup serius karena molekul-molekul asam benzoat yang tidak mengalami disosiasi diduga merupakan komponen aktif yang mematikan (Destrosier, $1988: 388)$.

Dari hasil penelitian, tidak ditemukan adanya pengawet sorbat pada sirup rasa marquisa yang diuji di Laboratorium Pengujian Pangan dan Bahan Berbahaya, ini terbukti dari kromatogram yang dihasilkan oleh HPLC tidak menunjukkan respon puncakatau respon puncak yang menandakan adanya pengawet sorbat pada sirup ini.

Dari data pada Tabel 4.3 diperoleh kadar pemanis sakarin yang bervariasi pada masingmasing sampel yaitu berkisar antara 434,62-1029,24 ppm. Jika kadar tersebut dibandingkan dengan batas maksimum yang diizinkan oleh pemerintah melalui Peraturan Menteri Kesehatan RI No. 722/Menkes/PER/IX/88, dan Standar Nasional Indonesia (SNI) 01-3544-1994, maka kadar pemanis sakarin pada masing-masing sampel minuman sirup rasa marquisa ini dapat dikatakan tidak memenuhi syarat, karena menurut Peraturan Menteri Kesehatan RI No. 722/Menkes/PER/IX/88, dan Standar Nasional Indonesia (SNI) 01-3544-1994, pemanis sakarin pada minuman sirup sama sekali tidak diperbolehkan. Jika minuman sirup rasa marquisa yang mengandung pemanis sakarin ini dikonsumsi oleh masyarakat, dapat menimbulkan gangguan kesehatan yang cukup serius. Menurut penelitian, penggunaan sakarin dapat merangsang terjadinya tumor pada kandung kemih (Winarno, $2002: 218$ ).

Penggunaan pengawet dan pemanis sintetis yang berlebihan pada minuman sirup ini diduga karena beberapa faktor yaitu :

1) kurangnya pengetahuan produsen mengenai batas maksimum penggunaan benzoat dan sakarin pada minuman sirup yang telah ditetapkan oleh Departemen Kesehatan melalui Peraturan Menteri Kesehatan RI No.722/Menkes/Per/88, dan Standar Nasional Indonesia (SNI) 01-3544-1994).

2) produsen tidak mentakar dengan baik penggunaan benzoat sebagai pengawet pada minuman sirup, sehingga terjadi kelebihan kadar pengawet pada minuman sirup ini.

3) faktor komersial, dimana penggunaan sakarin sebagai pemanis dapat menekan biaya produksi karena sakarin memiliki rasa manis yang jauh lebih besar daripada gula tebu sehingga produsen tidak perlu menggunakan gula tebu sebagai pemanis pada minuman sirup, ini tentu saja dapat menguntungkan para produsen.

Mengingat penggunaan pengawet dan pemanis sintetis yang berlebihan dapat menimbulkan masalah kesehatan yang cukup serius maka perlu adanya usaha untuk menekan penggunaan pengawet dan pemanis sintetis. Salah satunya adalah dengan memberikan penyuluhan kepada produsen agar mentakar dengan baik penggunaan pengawet dan pemanis sintetis sehingga kadarnya tidak melebihi batas maksimum yang telah ditetapkan oleh 
Depatemen Kesehatan, sehingga kesehatan konsumen tidak dirugikan akibat penggunaan pengawet dan pemanis sintetis yang berlebihan.

\section{Simpulan dan Saran}

Dari hasil penelitian maka dapat disimpulkan hal-hal sebagai berikut: Minuman sirup rasa marquisa yang diuji di Laboratorium Pangan dan Bahan Berbahaya BBPOM Denpasar, dan disampling di pasar Badung oleh bagian Pemeriksaan dan Penyelidikan (Pemdik) mengandung pengawet benzoat dengan kadar yang bervariasi yaitu antara 1291,31-1632,40 ppm, dan pemanis sakarin dangan kadar berkisar antara 434,62-1029,24 ppm. Tetapi tidak mengandung pengawet sorbat. Kadar bahan pengawet benzoat, dan pemanis sakarin pada minuman sirup rasa marquisa yang diuji di Laboratorium Pangan dan Bahan Berbahaya BBPOM Denpasar melebihi batas maksimum yang diperbolehkan oleh Departemen Kesehatan melalui Peraturan Menteri Kesehatan No. 722/Menkes/PER/88, dan Standar Nasional Indonesia (SNI) 01-35441994, sehingga minuman sirup rasa marquisa ini dapat dikatakan tidak aman untuk dikonsumsi oleh masyarakat.

Dari penelitian yang telah dilakukan maka, saran yang dapat penulis sampaikan pada kesempatan ini adalah sebagai berikut: Kepada para konsumen agar lebih berhati-hati dalan memilih minuman sirup yang akan dikonsumsi agar terhindar dari gangguan kesehatan yang cukup serius akibat penggunaan pengawet dan pemanis sintetis yang berlebihan. Dan agar dilakukan penelitian lainnya mengenai zat aditif yang dapat menimbulkan gangguan kesehatan yang cukup serius bagi masyarakat, seperti : zat warna, penyedap rasa, pemutih, pengental, dan lain sebagainya.

\section{Daftar Pustaka}

Anonim. 1998. Metode Analisis Bahan Pangan. Jakarta : Badan Pengawasan Obat dan Makanan.

Buckle, K. A. et al. 1987. Ilmu Pangan. Terjemahan Hari Purnomo dan Adiono. Food Science. 1985. Cetakan ke-2 Jakarta : UI Press.

Destrosier, N. W. 1988. Teknologi Pengawetan Pangan. Terjemahan Muchji Muljoharjo. The Tecnologi of Food Preservasion. 1969. Cetakan ke-3. Jakarta : UI Press.

Hudaya, S. 1983. Dasar-dasar Pengawetan I.Jakarta : Departemen Pendidikan dan Kebudayaan.

Imam dan Sukanto. 1999. Konsentrasi Maksimum Bahan Pengawet. http://www. Agribisnis.deptan.go.id/pustaka/teknopro.

Lies. 1997.Jenis Zat Aditif yang dilarang dan dibatasi penggunaannya . http://www. Agribisnis.deptan.go.id/pustaka/teknopro.

Peraturan Menteri Kesehatan RI No: 722/Menkes/PER/IX/88. Tentang Bahan Tambahan Makanan. 1990. Jakarta : Departeman Kesehatan Republik Indonesia.

Sopamena, O. 1999. Pengaruh Kalium Sorbat Terhadap Daya Simpan Tahu. Skripsi. (tidak diterbitkan). Jurusan Pendidikan Kimia, STKIP Singaraja.

Standar Nasional Indonesia 01-3544 tentang Syarat Mutu Sirup. 1994. Jakarta : Departemen Perindustrian dan Perdagangan RI.

Sujiono, 1999 http :// www.republika.co.id/suplemen/cetak

Winarno, F. G. 1986 Kimia Pangan dan Gizi. Jakarta : PT Gramedia Pustaka Umum. 